\title{
Exploring Reproductive Health Education Needs in Infertile Women in Iran: A Qualitative Study
}

\author{
Zohreh Khakbazan', Raziyeh Maasoumi ${ }^{1,2}$, Zahra Rakhshaee ${ }^{1,3}$, Saharnaz Nedjat ${ }^{4}$ \\ ${ }^{1}$ Department of Reproductive Health, School of Nursing and Midwifery, Tehran University of Medical Sciences, Tehran, Iran; ${ }^{2}$ Nursing and Midwifery \\ Care Research Center, School of Nursing and Midwifery, Tehran University of Medical Sciences, Tehran, Iran; ${ }^{3}$ Department of Nursing and Midwifery, \\ Rasht Branch, Islamic Azad University, Rasht, Iran; ${ }^{4}$ Epidemiology and Biostatistics Department, School of Public Health, Tehran University of \\ Medical Sciences, Tehran, Iran
}

Objectives: An inadequate understanding of infertility can affect individuals' self-efficacy and ability to perform self-care; thus, reproductive health education is an important part of infertility treatment. The present qualitative study aimed to explore the experiences and educational needs of infertile women with regard to reproductive health.

Methods: In this qualitative study, we utilized a content analysis approach. Purposive sampling was performed to ensure maximum diversity. In total, 23 individual interviews were conducted with 20 Iranian women with infertility and 3 key informants between July 2018 and February 2019 in northern Iran. Data were collected through in-depth, semi-structured interviews. Data analysis was performed using a conventional content analysis approach.

Results: Reproductive health education needs were identified by analyzing interview data from 4 main categories: familiarity with the fertility process and preparation for pregnancy, recognition of infertility and expectations around seeking treatment, recognition of preventive actions associated with reproductive health, and correction of false beliefs. Recognizing the causes of infertility and understanding the different approaches to infertility treatment are among the most important educational needs of infertile women. The potential for neglect of health-related issues due to concerns about fertility and the maternal experience necessitates education about preventive measures for cervical cancer, breast cancer, and sexually transmitted infections. Correcting misconceptions, including those related to contraceptives and traditional medicine, can also help promote reproductive health.

Conclusions: In infertile women, the educational needs associated with reproductive health are multifaceted. Satisfying these needs can help achieve optimal treatment results and promote reproductive health.

Key words: Reproductive health, Education, Infertility, Iran

\section{INTRODUCTION}

Received: February 24, 2020 Accepted: June 30, 2020

Corresponding author: Zahra Rakhshaee, PhD

Department of Reproductive Health, School of Nursing and Midwifery, Tehran University of Medical Sciences, Tehran 1419733171, Iran

E-mail: rakhshaeez@yahoo.com

This is an Open Access article distributed under the terms of the Creative Commons Attribution Non-Commercial License (https://creativecommons.org/licenses/by$\mathrm{nc} / 4.0 /$ ) which permits unrestricted non-commercial use, distribution, and reproduction in any medium, provided the original work is properly cited.
Infertility is defined as the absence of pregnancy after 1 year or more of regular intercourse without the use of contraception. According to the World Health Organization, approximately $10 \%$ of women worldwide have infertility [1]. In Iran, the prevalence rates of primary and secondary infertility are estimated to be $20.2 \%$ and $4.9 \%$, respectively, constituting a prevalence that is higher than the global level [2].

Infertility is a long process, and knowledge about their own 
medical condition and infertility in general can make affected individuals more informed and positive [3] and familiar with the treatment process [4]. Inadequate knowledge about health issues, including infertility, can negatively affect individuals' self-efficacy in adhering to their care plans [5]. The amount and quality of information is one of the most important factors that impacts patient responses to infertility treatment. Conversely, a lack of information can be an obstacle to treatment by creating or exacerbating anxiety [4]. According to previous studies [6-8], patients' knowledge and understanding of the causes and treatments of infertility are very poor. Infertile women have little knowledge of modern treatments and, despite often being strongly motivated to treat the condition and spend large sums, they suffer from a lack of awareness of treatment options and confusion about which treatment to choose [8]. Therefore, researchers consider education about fertility and methods of infertility treatment to be complementary to medical interventions [7-9]. The need for reproductive health education as part of the management and treatment of infertility is extremely important. Particularly in developing countries, where the dignity of women is often closely tied to fertility outcomes, infertility treatment should include education and counseling on reproductive health and treatment. Such interventions are recommended to overcome the barriers to treatment and to improve the provision of health services [4]. Furthermore, one of the most important responsibilities of health care providers is to identify and meet patients' educational needs in order to empower patients, raise the standards and increase the quality of patient-centered care [10], and increase patient satisfaction [11].

Since reproductive health needs and information are influenced by culture and socioeconomic conditions [12], and since the different dimensions of patients' educational needs cannot be investigated with quantitative studies alone, the present study was conducted using a qualitative approach and aimed to explore the reproductive health-related educational needs of women with infertility in Iran.

\section{METHODS}

This qualitative study utilized a conventional content analysis approach and was conducted at infertility centers in the city of Rasht (in northern Iran) between July 2018 and February 2019.

\section{Study Design}

The participants of the present study were 20 women with infertility and 3 women's healthcare providers in the field of infertility ( 2 midwives and 1 gynecologist). Eligible participants were found through infertility clinics and were recruited directly.

Sampling was purposive and was designed to yield maximum variety with respect to age; level of education; employment status; socioeconomic status; and the cause, type, and duration of infertility. Diversity in sampling was based on these factors because they impact women's awareness and information needs. In addition, the inclusion criteria were Iranian women with primary or secondary infertility (as diagnosed by a specialist physician), willingness to participate in the study and provide informed consent, and ability to understand, speak, and communicate in the interview in the Persian language. The exclusion criterion was unwillingness to participate in every stage of research. In this study, infertile women and key informants (as information-rich participants) were used. Since qualitative studies are designed to explore the meaning of reality, participants with relevant knowledge and life experiences should be a rich source of information about the concept under study [13].

In-depth semi-structured individual interviews with infertile women and key informants were conducted to collect data. Interviews were conducted by the third author (ZR), a woman $\mathrm{PhD}$ candidate in the field of reproductive health who is familiar with qualitative research, has 15 years of work experience in reproductive health, and is interested in the research topic. The other authors are experts in qualitative studies. In addition, the first and second authors have PhDs in reproductive health and are assistant professors. Prior to data collection, an interview guide was prepared based on a literature review and the experience of the researchers. The interview guide was used to explore the experiences of the participants with regard to their information needs related to reproductive health. The interviews contained a number of open and general questions.

Some of the questions for patients and key informants were as follows:

What information are you/women with infertility looking for about infertility and fertility issues?; What information do you/ women with infertility need about fertility and reproductive health?; Could you tell me your thoughts about reproductive health?; What are your thoughts about ideal reproductive health education for women with infertility?; What information do you/women with infertility expect from a health care provider with regard to reproductive education?; Some ques- 
tions were asked to clarify explanations, including: Could you tell me an example?; and May you explain more?

The places and times of the interviews were selected based on the participants' preferences. Before the start of the interview, confidentiality, the aims of the study, and the reasons behind the research were discussed with the participants. The participants were also informed that they were free to participate in the study or to discontinue participation, and written informed consent was provided by each participant. Using a questionnaire, information on participants' demographic characteristics and infertility status was obtained. All interviews were conducted individually, face-to-face, in a private room at the infertility clinic. Interviews were audio-recorded with the participants' permission. The duration of each interview ranged from 30 minutes to 60 minutes. Field notes were taken during the interview, with the researcher recording observations about non-verbal behaviors, encounters, and interactions. The sampling procedure continued until data saturation, which was considered to be the point at which no new data were obtained from the interviews. A total of 23 individual interviews were conducted, first with 20 infertile women and then with 3 key informants.

\section{Data Analysis}

Data were subjected to conventional content analysis according to the approach described by Graneheim and Lundman [14]. Data analysis was performed manually and simultaneously with data collection. The interviews were transcribed verbatim by the third author. The texts were read several times to identify the general ideas. Meaning units were identified, related meaning units were combined, and codes were generated. Similar codes were merged, and those with related meanings were grouped into subcategories. After comparing the subcategories, those that were conceptually similar were combined to form a main category [14].

\section{Trustworthiness}

To ensure the trustworthiness of the data, we considered credibility, dependability, conformability, transferability, and authenticity [15]. Credibility was achieved by spending sufficient time on data collection (approximately 7 months), ensuring diversity of participants, and including member checking (in which transcripts were returned to the participants for comment or correction). To confirm the validity of the data, coded interviews were conducted with 4 of the participants, and their final opinions were determined. Members of the research team actively transcribed and analyzed the results, a process that included reviewing interviews and codes, discussing the findings, and compiling the final results. Dependability and conformability were increased through external checking and peer debriefing; accordingly, 2 expert qualitative researchers and 2 external supervisors evaluated the transcripts, codes, and categories to identify any discrepancies in the coding process. With regard to transferability, purposive sampling was used with the goal of yielding maximum variety. Authenticity was evaluated through member checking, in which participants compared the results documented by the research team with their own views.

\section{Ethics Statement}

This study received ethical approval (IR.TUMS.FNM.REC.1397. 066) from the Committee of Faculty of Nursing and Midwifery of Tehran University of Medical Sciences. All participants provided written consent to participate in the study. Interviews were conducted in a private room in an infertility center, and confidentiality was ensured.

\section{RESULTS}

The results were obtained by analyzing information obtained from 23 interviews (conducted with 20 infertile women and 3 key informants). The infertile women in this study ranged in age from 25 years to 46 years, with a mean age of 33.35 years. Of the 20 women with infertility, 14 had primary infertility and 6 had secondary infertility. Table 1 shows the characteristics of the participants.

Education needs associated with reproductive health were identified by analyzing interview data in 4 main categories: familiarity with the fertility process and preparation for pregnancy (with 3 subcategories); recognition of infertility and expectations around seeking treatment (with 4 subcategories); recognition of preventive actions related to reproductive health (with 2 subcategories); and correction of false beliefs (with 2 subcategories). The categories and subcategories are shown in Table 2.

\section{Familiarity With the Fertility Process and Preparation for Pregnancy}

Most participants were interested in learning about the reproductive system, menstrual cycle, ovarian function, and ovulation time to better understand their fertility status and to 
Table 1. Summary of the participants' demographic characteristics

\begin{tabular}{|c|c|c|c|c|c|c|c|c|c|}
\hline $\begin{array}{l}\text { No. of } \\
\text { participant }\end{array}$ & $\begin{array}{c}\text { Age } \\
(y)\end{array}$ & Education level & Education & $\begin{array}{l}\text { Duration of } \\
\text { marriage }(y)\end{array}$ & $\begin{array}{l}\text { Duration of } \\
\text { infertility }(y)\end{array}$ & $\begin{array}{c}\text { Type of } \\
\text { infertility }\end{array}$ & $\begin{array}{l}\text { Cause of } \\
\text { infertility }\end{array}$ & $\begin{array}{c}\text { Work } \\
\text { experience }(y)\end{array}$ & Clinics \\
\hline \multicolumn{10}{|c|}{ Characteristics of the infertile women $(n=20)$} \\
\hline P1 & 25 & Graduate degree & - & 3 & 3 & Primary & Woman & - & - \\
\hline $\mathrm{P} 2$ & 32 & Graduate degree & - & 5 & 3 & Primary & Woman & - & - \\
\hline P3 & 38 & High school diploma & - & 6 & 3 & Secondary & Man & - & - \\
\hline P4 & 30 & Graduate degree & - & 9 & 4 & Secondary & Woman/man & - & - \\
\hline P6 & 28 & Associate degree & - & 8 & 3 & Primary & Woman & - & - \\
\hline P7 & 42 & Graduate degree & - & 20 & 3 & Secondary & Man & - & - \\
\hline P8 & 36 & Graduate degree & - & 3 & 3 & Primary & Woman/man & - & - \\
\hline P9 & 33 & Associate degree & - & 11 & 3 & Secondary & Woman & - & - \\
\hline P10 & 41 & Graduate degree & - & 3 & 2 & Primary & Man & - & - \\
\hline P14 & 29 & Graduate degree & - & 5 & 5 & Primary & Woman & - & - \\
\hline P15 & 32 & Graduate degree & - & 5 & 3 & Secondary & Unknown cause & - & - \\
\hline P16 & 27 & Graduate degree & - & 4 & 2 & Primary & Unknown cause & - & - \\
\hline P17 & 44 & Graduate degree & - & 10 & 5 & Secondary & Unknown cause & - & - \\
\hline P18 & 29 & High school diploma & - & 6 & 6 & Primary & Man & - & - \\
\hline P19 & 35 & Graduate degree & - & 7 & 7 & Primary & Man & - & - \\
\hline P20 & 31 & High school diploma & - & 7 & 7 & Primary & Woman & - & - \\
\hline \multicolumn{10}{|c|}{ Characteristics of the key informants $(n=3)$} \\
\hline P21 & 37 & Graduate degree & Midwifery & - & - & - & - & 12 & Private \\
\hline
\end{tabular}

Table 2. Categories and subcategories of reproductive health education needs in infertile women

\begin{tabular}{ll}
\hline Category & \multicolumn{1}{c}{ Subcategory } \\
\hline Familiarity with the fertility process and preparation for pregnancy & $\begin{array}{l}\text { Recognition of the anatomy and physiology of the reproductive system } \\
\text { Knowledge of the factors affecting fertility } \\
\text { Recognition of the actions required for pregnancy }\end{array}$ \\
Recognition of infertility and expectations around seeking treatment & $\begin{array}{l}\text { Recognition of the need for infertility counseling } \\
\text { Information needs about the causes of infertility and its diagnostic methods } \\
\text { Recognition of infertility treatment approaches }\end{array}$ \\
Rorrection of false beliefs & $\begin{array}{l}\text { Information about the complications and consequences of infertility treatments } \\
\text { Refeening for women reproductive cancer }\end{array}$ \\
& $\begin{array}{l}\text { Srevention of genital and sexually transmitted infections } \\
\text { Traditional medicine and fertility }\end{array}$ \\
\hline
\end{tabular}

take appropriate actions to increase the chance of pregnancy.

P7: "I really didn't know what the follicle was, or that we should consider ovulation for the planning of pregnancy, or when I'm ovulating."
The participants raised many points about the process of natural pregnancy, the time of fertilization, factors that impact fertility, and steps that can be taken to improve fertility. They brought up the duration of women fertility and the roles of 
age, nutrition, a healthy lifestyle, stress, and physical health in fertility. The women mentioned the need for information about prenatal care, tests, exercise, nutrition, and supplements in order to have a healthy pregnancy and give birth to a healthy child.

P1: "I would like to know what I should do to become pregnant sooner. What foods should leat?"

All participants asked about increasing the chance of becoming pregnant by targeting sexual activity, including the optimal time and frequency of sexual intercourse, the position of intercourse, and post-intercourse rest. Some women raised questions about the role of orgasm and the timing of orgasm in fertility.

P12: "When should we have sex to help get pregnant? How many times a week?"

\section{Recognition of Infertility and Expectations Around Seeking Treatment}

In this study, women raised issues about the correct definition of infertility, the use of specialized infertility service centers, and referral to a physician for follow-up and initiation of infertility treatment. Most infertile women expected that before the initiation of the treatment process, couples should be counseled in a quiet and private setting about their infertility, the stages of treatment, the length of treatment cycles, the success and failure rates of treatment, and the cost of treatment. According to participants, counseling couples would not only raise their awareness, but also create a sense of calm, responsibility, and mutual support during the therapeutic process.

P15: "A lot of stress stems from lacking information or having the wrong information. The doctor should explain from the very beginning what the treatment is, potential signs that it is going well or poorly, and how long the treatment takes. The doctor should talk to both members of the couple at the same time."

Most women described the need for information about the causes of infertility so they could address their concerns and take steps to solve the problem. Participants mentioned the role of a variety of factors, including inheritance, stress, obesity, and hormonal disorders. They needed to know about diagnostic methods of infertility, such as hormonal tests or sperm analysis, to be able to take appropriate and timely action.

P10: "I don't know why I am infertile...the doctor should tell us the reason why he or she is asking for a test or ultrasound."

All women cited the need for information about various infertility treatments as critical to their reproductive health. They mentioned the need for education about the types of infertility treatments; how the cause of infertility may impact treatment choice; intrauterine insemination (IUI) and how it is performed; in vitro fertilization (IVF), microinjection, and the steps involved in these techniques; the number of times the respective treatment could be performed; actions, considerations, and sexual intercourse during the infertility treatment process; and factors affecting treatment success.

P18: "Tell us more about infertility treatments. What is IUI? What is the difference between IVF and micro?... What are the considerations?"

Information about prescribed medications was another requirement raised by most women. They needed information in order to decrease concerns about the side effects of medications and infertility treatments. Some women raised various issues regarding the long-term effects of infertility treatments on the health of the individual and the fetus, fear of cancer and uterine and breast diseases, fear of a painful treatment process, and concerns about ovarian hyperstimulation syndrome and multiple pregnancy.

P17: "What is the function of this drug?...I'm afraid the drug I use will cause me trouble later, such as uterine and breast problems."

\section{Recognition of Preventive Actions Associated With Reproductive Health}

Most information needs were focused on issues related to infertility treatment; this caused other health-related issues, including reproductive health, to be neglected. Most women described having little knowledge about screening for women reproductive cancers, including cervical cancer and breast cancer, and information about Pap smears and mammography was limited to a physician's advice to perform them if needed. Therefore, they stated that given the importance of this issue, it is necessary to provide training on cervical and breast cancer prevention and screening.

P16: "I can't think of anything else besides my treatment...I heard that mammography is for breast cancer, and Pap smears are for cervical cancer. But I don't know much about them... However, it is important for a woman to know about them for her own health."

Most participants mentioned the need for information about genital infections and sexually transmitted diseases. Women also raised questions about the role of infections in infertility and required education about clinical symptoms, risk factors, and ways to prevent genital infections and sexually transmit- 
ted infections (STIS).

P7: "We don't know about many of the sexually transmitted diseases. How are they transmitted and how can they be prevented?"

\section{P12: "Can a long-lasting infection cause infertility?"}

\section{Correction of False Beliefs}

The majority of the participants reported using traditional medicine to attempt to improve fertility and increase their chances of pregnancy. They did so by using herbs or paying attention to the hot and cold nature of the diet. Some women attributed their infertility to the cold nature of the uterus and body, the consumption of cold-natured foods, or bathing during menstruation. According to the key informants, these women's beliefs interfered with their treatment processes.

P22 [key informant]: "Many of our patients have inaccurate beliefs. For example, a woman might say "I don't want to have a fetal transfer this month because my uterus is cold."

In this study, women noted a lack of information about contraceptive methods (including pills, ampoules, and intrauterine devices) and their complications. Participants mentioned that one reason for infertility is the use (long-term or otherwise) of certain contraceptive methods.

P9: "What are the side effects of contraceptive methods, such as pills and ampoules? Can they cause infertility?"

The key informants stated that by providing information about different contraceptive methods and correcting false beliefs in infertile women, one can help reduce these patients' feelings of guilt and mental distress.

\section{DISCUSSION}

According to the results of the data analysis, most reproductive health-related educational needs were focused on infertility and its treatment. The most important educational needs were a familiarity with fertility and its associated factors, prepregnancy actions to take, and methods of targeting sexual activity to promote pregnancy, as well as the ability to recognize infertility and understand its definition, causes, and treatment options. On a separate note, the potential for the neglect of health-related issues due to concerns around fertility and the maternal experience necessitates education about preventive actions, including those associated with cervical cancer, breast cancer, and STIs. Finally, due to some misconceptions that were present among the infertile women, the provision of information about complementary and alternative medicine (CAM) and contraceptive methods was also explored.

Qualitative research has shown that most men and women with infertility have a poor understanding of human biological reproductive processes [6,7]. A study in Iran similarly showed that infertile couples' knowledge of the reproductive systems and the natural fertility cycle is very low [16]. In the present study, all infertile women indicated a need for education about the menstrual cycle and the timing of ovulation to increase the chance of pregnancy. On this topic, a study by Hammarberg et al. [17] on the reproductive knowledge of women of reproductive age in Australia showed that only $32 \%$ of women were aware of the fertility window in the menstrual cycle. Knowledge about infertility and fertility is associated with education, and health promotion strategies are more effective when combined with educational interventions [18]. A study conducted by Jamshidimanesh et al. [19] demonstrated that providing educational programs about the reproductive system, fertility, and infertility increased the self-efficacy of infertile women.

In the present study, in accordance with the results of previous studies, the need for education about the causes and treatments of infertility was emphasized $[4,9,16,20]$. In most societies, infertility in the early stages of diagnosis is often attributed to (or blamed on) the woman [21]. Similarly, in traditional societies, infertility is recognized as a woman problem $[4,7]$, whereas in reality, both woman and man factors can lead to infertility [22]. Menstrual and ovulation disorders and uterine factors are among the most common causes of women infertility [23]. Causes of men infertility include the disruption of testicular or ejaculatory function, hormonal disorders, and genetic disorders [24]. In a study conducted in Iran, $48.8 \%$ of infertile women did not accept the diagnosed cause and considered it to be false [21]. Therefore, informing infertile women about the causes and treatments of infertility leads to better follow-up after infertility treatments and avoidance of traditional and unsafe methods [25]. Ezabadi et al. [16] emphasized the need to provide comprehensive educational programs on infertility at the first meeting with an infertile couple to reduce stress and encourage cooperation during treatment. It is also imperative to educate and empower infertile individuals with regard to the causes, treatments, and diagnostic and laboratory procedures associated with infertility to help them make informed decisions about assisted reproductive procedures.

In the present study, education about reproductive healthrelated preventive actions, such as those associated with can- 
cer and STIs, was explored as an educational need of infertile women. According to previous studies, poor health literacy and a lack of information were associated with a lack of followup after abnormal Pap smear results [26,27]. Murugappan et al. [28], in a retrospective cohort analysis study, showed that infertile women had a higher overall risk of developing cancer. Infertility is a risk factor for certain cancers, including breast, ovarian, and uterine cancers [29]. Anovulation, endometriosis, and nulliparity often accompany infertility and increase the risk of cancer as well [30]. Additionally, some cancers, including women reproductive and breast cancers, are hormone-dependent, offering an association between the use of fertility medication and cancer risk [31]. Infertile women may have a higher risk of certain cancers in the years after infertility evaluation; thus, continuous follow-up should be considered after the individual's reproductive goals have been achieved [28].

Most infertile women indicated a need for education about clinical symptoms and ways to prevent genital infections and STIs. Untreated STIs are one of the leading causes of women infertility in the world [32], and a study by Bennett et al. [9] showed that infertile women lacked information about the role of STIs in infertility. Thus, education of women is imperative to instill knowledge about STIs, and the provision of educational programs is critical [33].

In this study, the majority of women, in accordance with traditional medicine, used herbal medicines and/or "warm-natured" foods to improve fertility. Other studies have reported the use of traditional treatments and herbal medicines for infertility, especially in developing countries $[4,20]$. According to a study by Dattijo et al. [20] in Nigeria, $71.7 \%$ of individuals had used traditional treatments before visiting infertility clinics. Although little evidence exists to support these practices, current international research suggests that $29-96 \%$ of infertile women seek CAM in addition to conventional therapies [34-36]. Infertile women's understanding of their illness and physical condition influences their self-care behaviors, such as CAM use [37]. Therefore, healthcare providers should routinely ask infertile women about the use of herbal medicines and CAM, educate them about the risks and benefits of herbal therapy use, and provide appropriate advice [34].

In this study, some women pointed to the role of contraceptive methods in infertility. Fears of infertility or a delayed return to fertility after contraceptive use are well-documented and are often based on myths [38]. Contraceptive use, regardless of its duration and type, has no negative effects on the fertility of women. Thus, appropriate counseling is important to assure women that the methods are safe to use [39]. As such, providing information to infertile women can be useful in promoting reproductive health and correcting false beliefs.

Before the initiation of any educational program, the health needs and concerns of the target population must be specified. Patient education is one of the most important functions of the health-related professions. In infertile women, the educational needs associated with reproductive health are multifaceted, and satisfying those needs can help achieve optimal treatment results and promote reproductive health. The results of this study provide evidence that could aid in designing, implementing, and evaluating appropriate educational programs for infertile women. Therefore, in future studies, we recommend that educational interventions for infertile women be designed and implemented.

\section{Limitations}

This study was focused on infertile women in a city located in northern Iran. Therefore, similar studies should be conducted on populations of infertile women in different sociocultural contexts. Also, the participants in this study were infertile women who were seeking treatment, so further studies should be conducted on the reproductive health needs of infertile women who are not in the process of seeking help. Some women were reluctant to be interviewed due to a desire for privacy around reproductive issues. For this reason, the participants were assured that their information would be kept confidential, and the interviews were conducted in a private room.

\section{CONFLICT OF INTEREST}

The authors have no conflicts of interest associated with the material presented in this paper.

\section{FUNDING}

None.

\section{ACKNOWLEDGEMENTS}

This article is a part of a PhD thesis in reproductive health that was approved by the Tehran University of Medical Sciences. The authors would like to thank the research deputy of the Nursing and Midwifery Faculty of the Tehran University of Med- 
ical Sciences, the manager of the Mehr Infertility and Medical Institute of Rasht, Dr. Mehrafza, the research deputy of the Gilan University of Medical Sciences, and the participants for their sincere cooperation.

\section{AUTHOR CONTRIBUTIONS}

Conceptualization: ZK, RM, ZR. Data curation: ZR. Formal analysis: ZK, RM, ZR. Funding acquisition: None. Methodology: SN. Project administration: ZK, ZR. Visualization: ZK, ZR. Writing - original draft: ZR. Writing - review \& editing: ZK, RM, ZR, SN.

\section{ORCID}

Zohreh Khakbazan https://orcid.org/0000-0001-7471-0396

Raziyeh Maasoumi https://orcid.org/0000-0002-4986-4104

Zahra Rakhshaee https://orcid.org/0000-0002-9792-153X

Saharnaz Nedjat https://orcid.org/0000-0002-0966-727X

\section{REFERENCES}

1. World Health Organization. Revised glossary on assisted reproductive terminology (ART) [cited 2020 Feb 1]. Available from: https://www.who.int/reproductivehealth/publications/infertility/art_terminology2/en/.

2. Akhondi MM, Ranjbar F, Shirzad M, Behjati Ardakani Z, Kamali K, Mohammad K. Practical difficulties in estimating the prevalence of primary infertility in Iran. Int J Fertil Steril 2019;13(2): 113-117.

3. Domar A. Coping with the stress of infertility [cited 2020 Sep 10]. Available from: http://familybuilding.resolve.org/site/DocServer/15_Coping_with_the_Stress_of_Infertility.pdf?docID= 5705.

4. Dyer SJ, Abrahams N, Hoffman M, van der Spuy ZM. Infertility in South Africa: women's reproductive health knowledge and treatment-seeking behaviour for involuntary childlessness. Hum Reprod 2002;17(6):1657-1662.

5. Aghamohammdian Sharbaf HR, Zarezade Kheibari S, Horouf Ghanad M, Hokm Abadi ME. The relationship between perfectionism and sexual function in infertile women. Iran J Obstet Gynecol Infertil 2014;17(97):9-17 (Persian).

6. Bennett LR. Infertility, womanhood and motherhood in contemporary Indonesia: understanding gender discrimination in the realm of biomedical fertility care. Intersections 2012;(28).
7. Dyer SJ. Abrahams N, Mokoena NE, van der Spuy ZM. 'You are a man because you have children': experiences, reproductive health knowledge and treatment-seeking behaviour among men suffering from couple infertility in South Africa. Hum Reprod 2014;19(4):960-967.

8. Vedadhir A, Rahmani M, Dabbagh T. Infertility as a socio-cultural issue: understanding and lived experience of infertile women seeking treatment. J Soc Probl Iran 2017;7(2):159-175 (Persian).

9. Bennett LR, Wiweko B, Bell L, Shafira N, Pangestu M, Adayana $\mathrm{IB}$, et al. Reproductive knowledge and patient education needs among Indonesian women infertility patients attending three fertility clinics. Patient Educ Couns 2015;98(3):364-369.

10. Schmidt L, Holstein BE, Boivin J, Sångren $H$, Tjørnhøj-Thomsen T, Blaabjerg J, et al. Patients' attitudes to medical and psychosocial aspects of care in fertility clinics: findings from the Copenhagen Multi-centre Psychosocial Infertility (COMPI) Research Programme. Hum Reprod 2003;18(3):628-637.

11. Souter VL, Penney G, Hopton JL, Templeton AA. Patient satisfaction with the management of infertility. Hum Reprod 1998; 13(7):1831-1836.

12. Asadi-Lari M, Packham C, Gray, D. Need for redefining needs. Health Qual Life Outcomes 2003;1(1):34.

13. Polit DF, Beck CT. Nursing research: principles and methods. 7th ed. Philadelphia: Lippincott; 2004, p. 375-393.

14. Graneheim UH, Lundman B. Qualitative content analysis in nursing research: concepts, procedures and measures to achieve trustworthiness. Nurse Educ Today 2004;24(2):105-112.

15. Polit DF, Beck CT. Resource manual for nursing research: generating and assessing evidence for nursing practice. 10th ed. Philadelphia: Wolters Kluwer; 2017, p. 312-350.

16. Ezabadi Z, Mollaahmadi F, Mohammadi M, Omani Samani R, Vesali S. Identification of reproductive education needs of infertile clients undergoing assisted reproduction treatment using assessments of their knowledge and attitude. Int J Fertil Steril 2017;11(1):20-27.

17. Hammarberg K, Setter T, Norman RJ, Holden CA, Michelmore J, Johnson L. Knowledge about factors that influence fertility among Australians of reproductive age: a population-based survey. Fertil Steril 2013;99(2):502-507.

18. Bunting L, Tsibulsky I, Boivin J. Fertility knowledge and beliefs about fertility treatment: findings from the International Fertility Decision-making Study. Hum Reprod 2013;28(2):385-397.

19. Jamshidimanesh M, Alimanesh N, Moghaddam ZB, Haghani H. Effect of an educational package on self-efficacy of infertile 
women. Payesh 2015;14(2):227-237 (Persian).

20. Dattijo L, Andreadis N, Aminu B, Umar N, Black K. Knowledge of infertility among infertile women in Bauchi, Northern Nigeria. Int J Women's Health Reprod Sci 2016;4(3):103-109.

21. Norouzi S, Motlagh Z, Masoumi N, Tavassoli E, Moghaddam F. Educational need assessment of infertile women admitted to Yazd reproductive sciences institute. Int J Women's Health Reprod Sci 2017;5(2):123-128.

22. Olive K, Sekar KP, Susila C. Level of anxiety among women with infertility problems, at Pondicherry city hospital, Puducherry: a descriptive study. Iran J Child Neurol 2014;1(1):48-51.

23. Masoumi SZ, Parsa P, Darvish N, Mokhtari S, Yavangi M, Roshanaei $G$. An epidemiologic survey on the causes of infertility in patients referred to infertility center in Fatemieh Hospital in Hamadan. Iran J Reprod Med 2015;13(8):513-516.

24. Centers for Disease Control and Prevention. Infertility FAQs [cited 2020 Apr 1]. Available from: https://www.cdc.gov/reproductivehealth/infertility.

25. Sami N, Saeed Ali T. Perceptions and experiences of women in Karachi, Pakistan regarding secondary infertility: results from a community-based qualitative study. Obstet Gynecol Int 2012; 2012:108756.

26. Sharp LK, Zurawski JM, Roland PY, O'Toole C, Hines J. Health literacy, cervical cancer risk factors, and distress in low-income African-American women seeking colposcopy. Ethn Dis 2002; 12(4):541-546.

27. Lindau ST, Tomori C, Lyons T, Langseth L, Bennett CL, Garcia P. The association of health literacy with cervical cancer prevention knowledge and health behaviors in a multiethnic cohort of women. Am J Obstet Gynecol 2002;186(5):938-943.

28. Murugappan G, Li S, Lathi RB, Baker VL, Eisenberg ML. Risk of cancer in infertile women: analysis of US claims data. Hum Reprod 2019;34(5):894-902.

29. Kroener L, Dumesic D, Al-Safi Z. Use of fertility medications and cancer risk: a review and update. Curr Opin Obstet Gynecol 2017;29(4):195-201.

30. Practice Committee of the American Society for Reproductive
Medicine. Fertility drugs and cancer: a guideline. Fertil Steril 2016;106(7): 1617-1626.

31. Collaborative Group on Hormonal Factors in Breast Cancer. Menarche, menopause, and breast cancer risk: individual participant meta-analysis, including 118964 women with breast cancer from 117 epidemiological studies. Lancet Oncol 2012; 13(11):1141-1151.

32. World Health Organization. Sexually transmitted infections (STIs); 2011 [cited 2012 Oct 8]. Available from: https://www. who.int/en/news-room/fact-sheets/detail/sexually-transmitted-infections-(stis).

33. Hossain M, Mani KK, Sidik SM, Shahar HK, Islam R. Knowledge and awareness about STDs among women in Bangladesh. BMC Public Health 2014;14:775.

34. James PB, Taidy-Leigh L, Bah AJ, Kanu JS, Kangbai JB, Sevalie S. Prevalence and correlates of herbal medicine use among women seeking care for infertility in Freetown, Sierra Leone. Evid Based Complement Alternat Med 2018;2018:9493807.

35. Hung YC, Kao CW, Lin CC, Liao YN, Wu BY, Hung IL, et al. Chinese herbal products for female infertility in Taiwan: a population-based cohort study. Medicine (Baltimore) 2016;95(11): e3075.

36. Özkan FS, Karaca A, Sarak K. Complementary and alternative medicine used by infertile women in Turkey. Afr J Reprod Health 2018;22(2):40-48.

37. Hwang JH, Kim YY, Im HB, Han D. Complementary and alternative medicine use among infertile women attending infertility specialty clinics in South Korea: does perceived severity matter? BMC Complement Altern Med 2019;19(1):301.

38. Ochako R, Mbondo M, Aloo S, Kaimenyi S, Thompson R, Temmerman $\mathrm{M}$, et al. Barriers to modern contraceptive methods uptake among young women in Kenya: a qualitative study. BMC Public Health 2015;15:118.

39. Girum T Wasie A. Return of fertility after discontinuation of contraception: a systematic review and meta-analysis. Contracept Reprod Med 2018;3:9. 